\title{
Virus-induced gene silencing and its application in plant functional genomics
}

\author{
HUANG ChangJun, QIAN YaJuan, LI ZhengHe \& ZHOU XuePing* \\ State Key Laboratory of Rice Biology, Institute of Biotechnology, Zhejiang University, Hangzhou 310058, China
}

Received December 4, 2011; accepted December 13, 2011

\begin{abstract}
Virus-induced gene silencing is regarded as a powerful and efficient tool for the analysis of gene function in plants because it is simple, rapid and transformation-free. It has been used to perform both forward and reverse genetics to identify plant functional genes. Many viruses have been developed into virus-induced gene silencing vectors and gene functions involved in development, biotic and abiotic stresses, metabolism, and cellular signaling have been reported. In this review, we discuss the development and application of virus-induced gene silencing in plant functional genomics.
\end{abstract}

virus-induced gene silencing, gene function, gene expression

Citation: Huang C J, Qian Y J, Li Z H, et al. Virus-induced gene silencing and its application in plant functional genomics. Sci China Life Sci, 2012, 55: 99-108, doi: 10.1007/s11427-012-4280-4

In recent decades, abundant plant genome information has become available through genome sequencing and expressed sequence tag (EST) analysis. In the post-genome era, a major challenge is to determine gene functions. However, even in the model plant Arabidopsis, less than $10 \%$ of predicted genes have been identified and characterized functionally [1]. To knockout or reduce gene expression, traditional approaches for high-throughput reverse-genetic gene function screening include chemical induced mutation, random mutation, and T-DNA insert mutation. However, these methods may be hindered in the studies of non-model plants because of their large genome size, low transformation efficiency, and lack of a clear genetic background.

Compared with traditional methods, virus-induced gene silencing (VIGS) is a powerful, recently developed approach for plant loss-of-function assay that can overcome the above-mentioned problems [2,3]. A recombinant virus for VIGS, delivering a fragment of plant gene into plant

*Corresponding author (email: zzhou@zju.edu.cn) cells, can induce plant defense mechanism to silence both the targeted endogenous plant gene and the virus, through post-transcriptional gene silencing (PTGS). Gene functions can then be characterized by the sequence-specific phenotypes $[2,4]$. Combined with the abundant plant genome and EST sequences, VIGS will significantly accelerate the gene function identification in various plant species. More than 30 VIGS vectors have been developed, and these vectors have been widely used to uncover the functions of genes involved in basic cellular functions, metabolic pathways, development biology, plant-microbe interaction, and abiotic stress (Table 1) [5,6]. In this review, we will discuss the recent advances in the application of VIGS in plant functional genomics.

\section{Establishment and development of VIGS}

In 1997, van Kammen [7] first mentioned the term "VIGS", to describe the phenomenon of recovery from virus infection. Since then, the term "VIGS" has been used exclusively 
for the technique of using recombinant viruses to knockdown expression of endogenous genes [2,8]. In the early stages, most of the VIGS systems were based on RNA viruses. In 1995, Kumagai et al. [9] inserted a fragment of phytoene desaturase (PDS), a key enzyme of the carotenoid biosynthetic pathway, into the Tobacco mosaic virus (TMV) [9]. When this recombinant virus was inoculated into Nicotiana benthamiana, a blench phenotype in the leaves was observed and this phenomenon was caused by reduction in endogenous PDS mRNA. In 1998, similar results were obtained using another RNA virus, Potato $\mathrm{X}$ virus (PVX), carrying a fragment of the PDS cDNA [8]. Thus, VIGS is considered to be a useful technique for suppressing endogenous gene expression and uncovering plant gene functions. In 2001, a novel VIGS vector was established based on Tobacco rattle virus (TRV). TRV was demonstrated to induce more efficient silencing of transgenes and endogenous genes [10]. TRV could spread more vigorously throughout the entire plant, including meristem tissue, and the symptoms induced by TRV are much milder compared with other viruses [10]. The TRV vector has been widely used in gene function studies of tomato, tobacco, Petunia hybrida, chili pepper, Arabidopsis, and cotton plants (Table 1).

DNA viruses, such as geminiviruses, have also been successfully modified into VIGS vectors. In 1998, Robertson et al. used TGMV as a vector to determine whether episomal DNA could induce silencing of homologous, chromosomal genes. They modified the TGMV DNA-A component into a vector and induced silencing of the two marker genes, the sulfur (su), a magnesium chelatase required for chlorophyll formation, and the firefly luciferase (luc) gene [11]. Subse- quently, VIGS vectors were developed based on the DNA viruses African cassava mosaic virus (ACMV) and Cotton leaf crumple virus (CLCrV), which have been used for functional genomic studies in cassava and cotton plants $[12,13]$.

Subsequently, a novel VIGS vector was developed based on an RNA satellite virus, the U2 strain of TMV (STMV). The RNA satellite virus silencing vector was able to obtain pronounced and severe knockout phenotypes for 13 targeted endogenous genes involved in various biochemical pathways and expressed in different plant tissues [14]. The advantages of STMV as an excellent candidate VIGS vector are its small genome size and high replication rate in plants.

Tao et al. and Huang et al. reported induction of VIGS based on Tomato yellow leaf curl China virus (TYLCCNV) betasatellite (DNA $\beta$ ) and Tobacco curly shoot virus (TbCSV) alphasatellite (DNA1) $[15,16]$. They demonstrated that these modified satellite vectors could effectively suppress GFP in transgenic $N$. benthamiana and endogenous $\mathrm{Su}$ in plants, when co-agroinoculated with their helper viruses. These modified satellite vectors have been used to induce gene silencing in Nicotiana spp., Solanum lycopersicum, and Petunia hybrida plants [15-19].

VIGS vectors have not only been applied in dicotyledonous plants, but also in monocotyledonous plants. In 2002, VIGS was established in barley and wheat using Barley stripe mosaic virus (BSMV), where certain genes related to resistance against leaf rust or powdery mildew were characterized in barley [20]. Ding et al. [21] also showed that a modified VIGS vector based on Brome mosaic virus (BMV) could be used for the analysis of gene function in rice and maize.

Table 1 Various VIGS vectors and plant species used for gene silencing

\begin{tabular}{|c|c|c|c|}
\hline Virus vector & Plant species and tissue for inoculation & Inoculation method & References \\
\hline \multicolumn{4}{|l|}{ RNA virus } \\
\hline $\begin{array}{l}\text { Apple latent spherical } \\
\text { virus (ALSV) }\end{array}$ & $\begin{array}{l}\text { Nicotiana spp., Arabidopsis thaliana, Apple, Pear, } \\
\text { Solanum lycopersicum, Cucumis spp.: leaf; Legu- } \\
\text { minaceae: leaf; beanpod: seed }\end{array}$ & $\begin{array}{l}\text { Nicotiana spp. and Arabidopsis thaliana with sap } \\
\text { inoculation; soybean, apple and pear with particle } \\
\text { bombardment into seedlings using extracted } \\
\text { RNA from the virus infected plants }\end{array}$ & [22-24] \\
\hline $\begin{array}{l}\text { Brome mosaic virus } \\
\text { (BMV) }\end{array}$ & $\begin{array}{c}\text { Oryza sativa, Zea mays, Hordeum vulgare, Festuca } \\
\text { arundinacea, } N \text {. benthamiana: leaf }\end{array}$ & $\begin{array}{l}\text { Rub inoculation of in vitro transcripts for other } \\
\text { crops and vacuum infiltration for rice }\end{array}$ & {$[21,25,26]$} \\
\hline $\begin{array}{l}\text { Barley stripe mosaic } \\
\text { virus (BSMV) }\end{array}$ & $\begin{array}{l}\text { Brachypodium distachyum: root; Barely, Avena } \\
\text { species and Triticum aestivum: leaf }\end{array}$ & Rub inoculation of in vitro transcripts & {$[20,27-30]$} \\
\hline $\begin{array}{l}\text { Bean pod mottle virus } \\
\text { (BPMV) }\end{array}$ & $\begin{array}{l}\text { Glycine max: root, leaf and shoot; Phaseolus vul- } \\
\text { gari: leaf }\end{array}$ & $\begin{array}{l}\text { Rub inoculation of in vitro transcripts and parti- } \\
\text { cle bombardment }\end{array}$ & [31-33] \\
\hline $\begin{array}{l}\text { Cucumber mosaic } \\
\text { virus (CMV) }\end{array}$ & G. max: leaf and seed & $\begin{array}{c}\text { With rub inoculation of in vitro transcripts in } N \text {. } \\
\text { benthamiana and then inoculation of soybean } \\
\text { plants with extract sap }\end{array}$ & [34] \\
\hline $\begin{array}{l}\text { Cymbidium mosaic } \\
\text { virus (CymMV) }\end{array}$ & Phalaenopsis orchids: flower & Rub inoculation of in vitro transcripts & [35] \\
\hline Potato virus $\mathrm{X}(\mathrm{PVX})$ & $\begin{array}{l}\text { N. benthamiana: leaf; Solanum tuberosum: leaf, } \\
\text { root and tuber }\end{array}$ & Agro-inoculation & {$[8,36,37]$} \\
\hline Potato virus A (PVA) & N. benthamiana: leaf & $\begin{array}{l}\text { Rub inoculation of in vitro transcripts and parti- } \\
\text { cle bombardment }\end{array}$ & [38] \\
\hline $\begin{array}{l}\text { Pea early browning } \\
\text { virus (PEBV) }\end{array}$ & $\begin{array}{l}\text { Lathyrus odorata: leaf, shoot, root, flower and } \\
\text { beanpod; Medicago truncatula: leaf }\end{array}$ & Agro-inoculation & [39-41] \\
\hline $\begin{array}{l}\text { Poplar mosaic virus } \\
\text { (PopMV) }\end{array}$ & N. benthamiana: leaf & Agro-inoculation & [42] \\
\hline
\end{tabular}




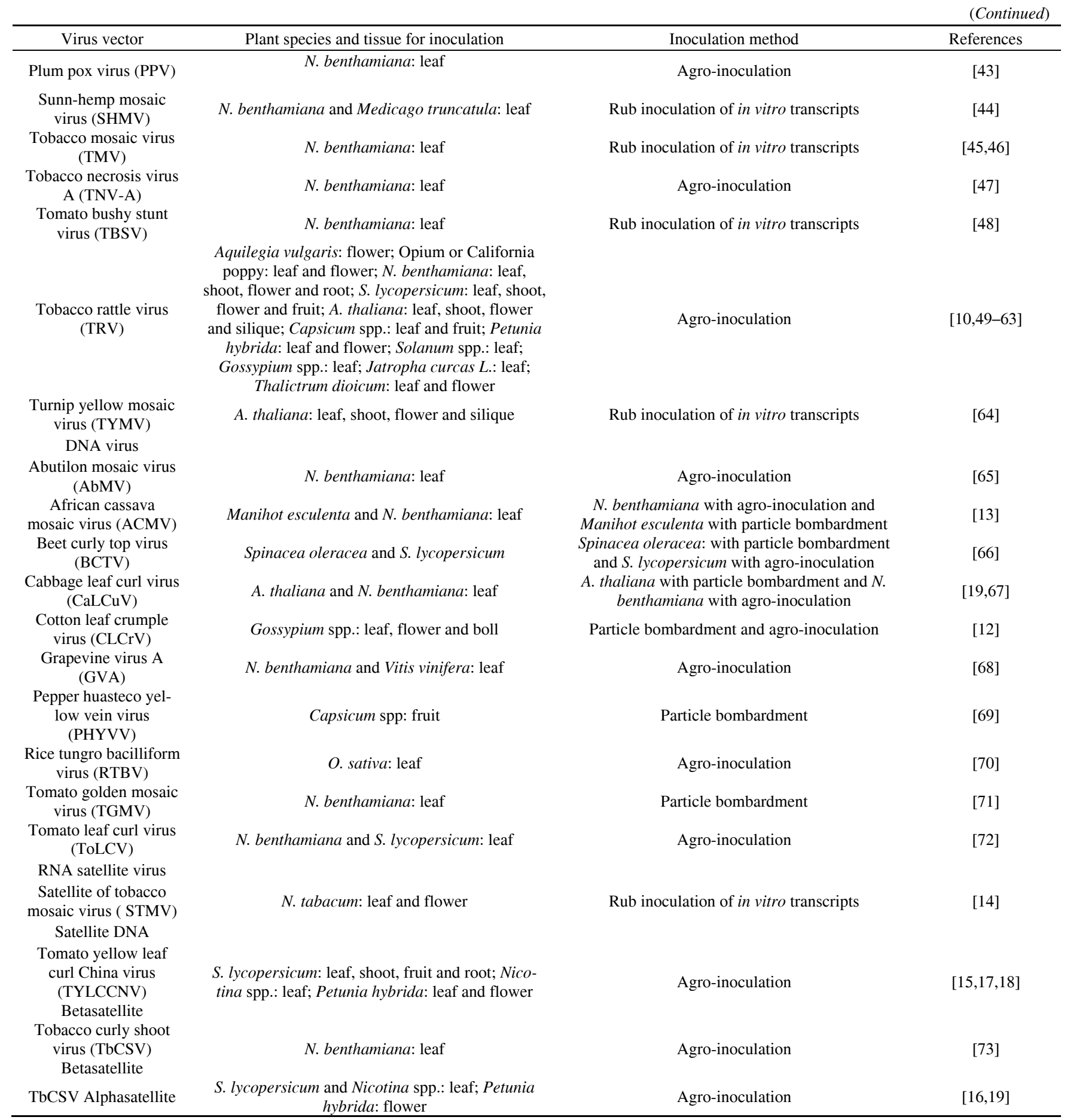

\section{Methodology and development of VIGS}

In a VIGS system, to suppress expression of an endogenous plant gene, a fragment of the gene to be silenced should be cloned and inserted into the VIGS vector and then inoculated into plants. The VIGS phenotype can be subsequently observed. Generally, to increase the efficiency of silencing, the VIGS system should be optimized.
First, the size of the inserted fragment of target endogenous gene may affect the efficiency of VIGS. Most VIGS vectors have the capacity to carry a fragment of length between 150 and $800 \mathrm{bp}$. VIGS vectors may fail to induce gene silencing if a fragment of more than $1500 \mathrm{bp}$ is inserted. Although some studies showed that a $23 \mathrm{bp}$ insertion was able to induce VIGS, fragments of 200-350 bp in length is usually chosen for VIGS to obtain higher silencing efficiency. Furthermore, some studies found that the orien- 
tation of the inserted gene fragment was also an important factor that could affect the efficiency of VIGS, with higher silencing efficiency being induced by a reverse oriented insertion compared with that of a forward oriented insertion. However, it is not applicable to all vectors. For example, the efficiency of the TYLCCNV DNA $\beta$ vector is the same whatever the orientation of the inserted fragment [19]. Additionally, the silencing efficiency could be significantly enhanced if the target fragment was constructed as a hairpin structure [74].

Selection of the target gene is important for VIGS. Evidence has shown that an improper gene fragment might induce off-target silencing, producing an inaccurate phenotype [75]. Many candidate fragments can be selected for silencing of a specific gene. However, if the target gene belongs to a gene family, some sequences may have conserved domains among different genes in the gene family, and the fragment of the target gene may have more than 23 bp that is homologous to other genes in the gene family resulting in the degradation of non-target genes. Therefore, a more specific fragment needs to be chosen. Generally, a fragment from UTR region is a good choice. On the other hand, the conserved domains should be chosen to avoid functional complementation by genes from the same family; in this case all the genes in the family are silenced [76].

The efficiency of gene silencing may be affected by different inoculation methods. The common methods used for inoculation are agro-infiltration, rub-inoculation with RNA transcripts, and particle bombardment (Table 1). For some viruses, susceptible plants will be inoculated firstly to multiply the virus, and then the sap or the virus RNA extract will be used to inoculate target plants. High silencing efficiency was reported using agrodrench, a method of watering the plant roots with agro-inocula directly [60]. Liu et al. [58] successfully induced the TRV vector into tomato by spraying a TRV agro-culture using an airbrush. Ding et al. reported that efficient gene silencing could be obtained by vacuum agro-infiltration in plants that are hard to inoculate by conventional methods. For fruits, direct injection with an agro-culture produces a more obvious silencing phenotype than inoculation of cotyledons or seedlings [53,77]. Some studies showed that efficient silencing could be induced by injecting plucked tomato, strawberry and bilberry fruits with an agro-culture containing VIGS vector [78-80], which is useful for studying gene functions during the post harvest stage. Co-inoculation of viral suppressors with VIGS vectors may also improve the silencing efficiency. When plants were inoculated with a mixture of VIGS vector and a gene-silencing suppressor, higher accumulation of virus in local inoculated cells induced a higher efficiency of silencing in systemic leaves. With the establishment of more and more new virus inoculation methods, VIGS will be applicable to more plant species.

Finally, environmental factors of plant growth will affect the efficiency of gene silencing. At higher temperatures, the accumulation of virus is significantly reduced, which impairs the efficiency of virus induced silencing. On the other hand, lower temperatures lead to higher virus concentration and silencing efficiency. For TRV vectors, tomato plants should be kept at less than $21^{\circ} \mathrm{C}$. Lower temperature and humidity will increase silencing efficiency [12,54]. However, for some vectors, temperature is not so important, for example, both DNA $\beta$ and DNA 1 vectors can induce highly efficient silencing from 22 to $32^{\circ} \mathrm{C}[15,18]$.

\section{Validation of gene functions in different plant organs or tissues via VIGS}

The high efficiency of VIGS has led to its increasing use in uncovering the functions of hundreds of plant genes involved in defense response pathways, plant development, and metabolism. Recent progress in gene function identification by VIGS is detailed below.

\subsection{Genes involved in the defense response to patho- gens, insects, and abiotic stresses}

Plants grow in an environment surrounded by a diversity of microbes and abiotic stresses. A highly effective defense system has been evolved to resist potential attack by biotic and abiotic stresses. Previous studies have determined the functions of diverse plant genes involved in virus-, bacteria-, fungi-, and insect-resistance and stress responses.

In the study of plant resistance to virus infection, the most successful examples of using VIGS to uncover gene functions in defense response pathway was the $N$ gene against TMV and $R x$ gene against PVX. Up to now, a number of genes have been identified, such as $N R G 1, N b C A 1$, NbCAM1, NbrbohB, RAR1, EDS1, NPRI/NIM1, MEK1, $M A P K K, N T F 6, M A P K$, WRKY/MYB transcription factors, COII and CTRI genes [18,59,81-84]. The power of VIGS as a tool in reverse genetics is further manifested by the subsequent studies of the roles of BECLIN-1 and NRIPI in $N$-gene and RanGAP2 in $R x$-gene induced programmed cell death (PCD) [85-87]. Silencing of BECLIN-1 by TRV in $N$. benthamiana plants containing the $\mathrm{N}$ gene showed an unrestricted PCD response upon TMV infection [86]. NRIP1, which can directly interact with both the $N$ gene and the 50 $\mathrm{kD}$ helicase (p50) of TMV, is involved in pathogen recognition, and is required for $N$ gene-mediated complete resistance to TMV [85]. The interaction of $R x$ and RanGAP2 in $N$. benthamiana or potato is required for extreme resistance to PVX, where RanGAP2 is part of the $R x$ signaling complex [87]. In addition, a number of host genes involved in virus replication and movement in plants have been identified by VIGS [17,88-93].

VIGS has also been applied to study plant resistance against fungi [94]. A series of host genes involved in Cladosporium fulvum-tomato resistance have been charac- 
terized [95]. NRCI and SlPLC4, and ACIKI and NbCAI genes have been proved to be necessary for $C f-4 / A v r 4$ and $C f-9 / A v r 9$ interactions, respectively, to elicit plant resistance [84,96-98]. Using a VIGS assay, Liu et al. [99] showed that $C I T R X$ is a negative regulator of the $C f-9 / A v r 9$ induced hypersensitive response (HR). Furthermore, LeMPK1, $L e M P K 2$, and LeMPK3 are activated during the Cf-4/Avr4induced HR [100]. Additionally, some genes related to defense responses and basal resistance against powdery mildew fungus [101,102], wheat leaf rust fungus [29,103], Colletotrichum destructivum, C. orbiculare [104], and tobacco blue mold fungus [105] have been identified in dicotyledonous or monocotyledonous plants.

Applications of VIGS in studies of plant resistance against bacteria have been reported. Many new genes in the pathway of the Pto-mediated defense response against Pseudomonas syringae have been discovered in tomato, i.e., NbCA1, NPR1, TGA1a, TGA2.2, MEK1, MEK2, and NTF6 $[84,106]$. Recently, the function of COR, a virulence factor of $P$. syringae, was revealed by VIGS. In addition, the roles of SGT1 and SlALC1, two key genes in the coronatine/jasmonate (JA) pathway, and inducible NO synthase (iNOS) in resistance against $P$. syringae have been uncovered [107]. In tobacco plants, the important roles of NbHSP90c-1, NbHSP70c-1, WIPK, and SIPK genes in non-host resistance to $P$. cichorii, and SGLP in resistance against Ralstonia solanacearum, have been demonstrated by VIGS [108-110]. In a study searching for genes required for defense responses against Xanthomonas campestris in plants, Bs4, SGT1, CaCYP450A, CaRING1, SIMKK2 and SIMPK2 genes have been characterized [111-115].

VIGS has also been successfully used to investigate the resistance of plants to nematode and herbivore attack, such as aphids and Manduca sexta. Some genes have been found to have important roles in resistance against nematodes and aphids, such as SlWRKY72a, HSP90, LeMPK2, LeMPK1, LeMPK3, SlSERK1, and SGT1 [116-120]. Suppressing threonine deaminase (TD) and germin-like, jasmonateresistant4 (JAR4) by VIGS confirmed that these genes have important roles in activating plant defenses to $M$. sexta [121,122]. MPK1 and MPK2, which are essential components of the systemic signal pathway, were shown by VIGS to be required for successful defense against herbivorous insects [123]. Using VIGS, $M K K 1, M E K 2$, and $B A K 1$ have been demonstrated to be involved in herbivore $M$. sexta-induced responses by regulating JA biosynthesis [124,125].

VIGS was used to identify genes that mitigate stress. late embryogenic abundant 4 (lea4) was shown to be involved in mitigating moisture stress [126]. SlGRX1 was reported to regulate abiotic tolerance against oxidative, drought, and salt stresses [127]. In pepper, CaOXRl was found to play roles in tolerance to high salinity and osmotic stress [128]. In tobacco plants, $\mathrm{NbPHB1}$ and $\mathrm{NbPHB2}$, two subunits of prohibitins, were found to have a crucial role in mitochondrial biogenesis and protection against stress and senes- cence in plant cells. NaHD2O has a role in responses to dehydration $[129,130]$. In addition, VIGS has been used to study water deficit-induced genes in peanut [131].

\subsection{Plant development related genes}

VIGS is a transient assay for suppressing gene expression; therefore, VIGS facilitates the study of genes whose loss of function could be lethal to plants. Up to now, many development-related genes have been characterized by VIGS. Recently, a study on the flowering of the opium poppy using VIGS indicated that PapsAG-1 has a role in stamen and carpel identity; however, the homologous gene, PapsAG-2, while displaying redundancy in these functions, has a distinctive role in the development of the septae, ovules, and stigmas [132]. In tobacco and Petunia hybrida plants, many flower development related genes, such as flowering time determine genes ( $F C A$ and $F Y$ ), floral organ identity genes (AP3 and DEFICIENS) [40,133,134] and flower development genes (NbMADS4-1, NbMADS4-2, PhPHB1 and PhPHB2) [135,136] have been identified by VIGS. In a study of leaf and shoot development, Kang et al. [137] showed that the silencing of the NbBPS1 gene resulted in growth retardation, abnormal leaf development, and cell death. This phenotype is different from the case of the Arabidopsis bps mutant. Bouvier et al. [138] used VIGS to suppress the expression of SAMT1 in N. benthamiana. The severe growth retardation phenotype in silenced plants suggested that this methylation-related protein has an important role in plant development. The plant vascular development gene (RPN9 [93]), Retinoblastoma-related gene (RBR [139]), a plant root development gene [140] and some genes in meristem, such as Dt1 [141] and MLI [140] have been functionally characterized by VIGS. These results suggest that VIGS is one of the most powerful tools for the analysis of genes whose loss-of-function mutants cause embryonic and seedling-lethality [4-6].

\subsection{Cellular functions and metabolism}

VIGS has been used to study plant cellular functions and metabolic pathways, such as biotin, enzyme biosynthesis, and organic identity. Burton et al. and Held et al. used PVX and BSMV vectors, respectively, to study the function of Cellulose synthase (CesA) [142,143]. VIGS was also used to determine the genes involved in the biosynthesis of capsaicinoids (AT3, Comt, pAmt, and Kas) [69,144], D-apiose (UDP-D-apiose/UDP-D-xylose synthase, and AXS1) [145], flavin [146], histone $H 3$ [147], and key proteins in the RNA silencing pathway, such as Argonaute1- and Argonaute 4-like genes [148]. In addition, genes involved in the regulatory functions of PCD have been recently identified using VIGS, for example, the mitochondrial-associated hexokinase $H x k l$ gene [149], 20S proteasome, the 19S regulatory complex of the $26 \mathrm{~S}$ proteasome [150] and a regulatory gene 
of PCD (CDC5 [151]). VIGS has also been used to characterize cellular functions of genes involved in chloroplasts and mitochondria biogenesis [129,150,152-157], plastid biogenesis [138,150], peroxisome biogenesis [158], alkaloid biosynthesis [159-161], isoprenoid biosynthesis [162,163], ascorbic acid biosynthesis [164], sterol biosynthesis [36,165], and membrane biogenesis [166].

\section{Pros and cons of VIGS}

Compared with other genomic techniques, VIGS has several advantages: (i) VIGS is much faster. A notable characteristic of VIGS is that it can induce loss-of-function phenotype of a specific gene in a short period. Therefore, the gene function can be characterized quickly, obviating the tedious process of plant regeneration [5,6]. (ii) Plant transformation is avoided, which means that studies of gene function in plants that are difficult to transform (e.g., cotton and soybean) would be more productive once the VIGS system is established. (iii) VIGS permits the study of genes that are vital for plant viability. VIGS can be used at the seedling or early development stages, and has been proved a powerful tool in the analysis of genes whose mutations cause embryonic and seedling-lethality. VIGS is the only technique that permits the study of such plant genes that are involved in plant development. (iv) The expression of multiple genes with functional redundancy can be silenced simultaneously through VIGS using conserved domains. On the other hand, a specific region can be used for VIGS if just one gene among a gene family is intended to be silenced. (v) It allows quick comparison of the functions of homologous genes among different plant species at the same time, producing more accurate gene function identification [5,6].

VIGS also has some disadvantages or limitations. For example, (i) in most cases, the expression of gene cannot be completely inhibited through VIGS. Although the expression of the target gene is reduced, the residual expression of the target gene can be enough for its function. Therefore, for those genes, the loss-of-function phenotype cannot be observed through VIGS. (ii) VIGS requires prior knowledge of target gene sequence information. The efficiency of silencing may be compromised by redundant genes, unless the full genome or sufficient EST sequences are available. (iii) Genes expressed during germination or the early seedling stage cannot be analyzed by VIGS, because VIGS is usually performed on adult plants and most of the VIGS phenotype is not inherited. (iv) The efficiency may vary and the phenotype of VIGS is not very stable. Results may not be consistent among different experiments or different plants. To resolve this problem, it is common to use a marker gene that shows a visible silencing phenotype as a positive control.

\section{Conclusion and outlook}

Over the last 15 years, VIGS has been successfully used to discover and confirm gene functions in many plants, including both dicotyledonous and monocotyledonous plants. Further understanding of the mechanism of gene silencing and development of vectors for VIGS will lead to more plant species being studied by newly constructed VIGS systems, especially those that are hard to analyze by conventional approaches. Recently, more plant genomes have been sequenced, and new molecular biology techniques have been established for VIGS. For example, artificial miRNA silencing vectors have been used in VIGS, and a VIGS cDNA library was constructed using the gateway system $[135,167,168]$. With further technical improvements, VIGS will continue to be widely used in plant functional genomics.

This work was supported by the National Transgenic Research Projects of China (Grant No. 2009ZX08009-026B).

1 Matthew L. RNAi for plant functional genomics. Comp Funct Genomics, 2004, 5: 240-244

2 Baulcombe D C. Fast forward genetics based on virus-induced gene silencing. Curr Opin Plant Biol, 1999, 2: 109-113

3 Burch-Smith T M, Anderson J C, Martin G B, et al. Applications and advantages of virus-induced gene silencing for gene function studies in plants. Plant J, 2004, 39: 734-746

4 Robertson D. VIGS vectors for gene silencing: many targets, many tools. Annu Rev Plant Biol, 2004, 55: 495-519

5 Becker A, Lange M. VIGS—genomics goes functional. Trends Plant Sci, 2010, 15: 1-4

6 Purkayastha A, Dasgupta I. Virus-induced gene silencing: a versatile tool for discovery of gene functions in plants. Plant Physiol Biochem, 2009, 47: 967-976

7 van Kammen A. Virus-induced gene silencing in infected and transgenic plants. Trends Plant Sci, 1997, 2: 409-411

8 Ruiz M T, Voinnet O, Baulcombe D C. Initiation and maintenance of virus-induced gene silencing. Plant Cell, 1998, 10: 937-946

9 Kumagai M H, Donson J, della-Cioppa G, et al. Cytoplasmic inhibition of carotenoid biosynthesis with virus-derived RNA. Proc Natl Acad Sci USA, 1995, 92: 1679-1683

10 Ratcliff F, Martin-Hernandez A M, Baulcombe D C. Tobacco rattle virus as a vector for analysis of gene function by silencing. Plant $\mathrm{J}$, 2001, 25: 237-245

11 Kjemtrup S, Sampson K S, Peele C G, et al. Gene silencing from plant DNA carried by a geminivirus. Plant J, 1998, 14: 91-100

12 Tuttle J R, Idris A M, Brown J K, et al. Geminivirus-mediated gene silencing from cotton leaf crumple virus is enhanced by low temperature in cotton. Plant Physiol, 2008, 148: 41-50

13 Fofana I B, Sangare A, Collier R, et al. A geminivirus-induced gene silencing system for gene function validation in cassava. Plant Mol Biol, 2004, 56: 613-624

14 Gossele V, Fache I, Meulewaeter F, et al. SVISS - a novel transient gene silencing system for gene function discovery and validation in tobacco plants. Plant J, 2002, 32: 859-866

15 Tao X, Zhou X. A modified viral satellite DNA that suppresses gene expression in plants. Plant J, 2004, 38: 850-860

16 Huang C, Xie Y, Zhou X. Efficient virus-induced gene silencing in plants using a modified geminivirus DNA1 component. Plant Biotechnol J, 2009, 7: 254-265 
17 Cai X, Wang $\mathrm{C}, \mathrm{Xu} \mathrm{Y}$, et al. Efficient gene silencing induction in tomato by a viral satellite DNA vector. Virus Res, 2007, 125: 169_ 175

18 He X, Jin C, Li G, et al. Use of the modified viral satellite DNA vector to silence mineral nutrition-related genes in plants: silencing of the tomato ferric chelate reductase gene, FRO1, as an example. Sci China Ser C-Life Sci, 2008, 51: 402-409

19 Huang C J, Zhang T, Li F F, et al. Development and application of an efficient virus-induced gene silencing system in Nicotiana tabacum using geminivirus alphasatellite. J Zhejiang Univ Sci B, 2011, 12: 83-92

20 Holzberg S, Brosio P, Gross C, et al. Barley stripe mosaic virus-induced gene silencing in a monocot plant. Plant J, 2002, 30: 315-327

21 Ding X S, Schneider W L, Chaluvadi S R, et al. Characterization of a brome mosaic virus strain and its use as a vector for gene silencing in monocotyledonous hosts. Mol Plant Microbe Interact, 2006, 19: 1229-1239

22 Igarashi A, Yamagata K, Sugai T, et al. Apple latent spherical virus vectors for reliable and effective virus-induced gene silencing among a broad range of plants including tobacco, tomato, Arabidopsis thaliana, cucurbits, and legumes. Virology, 2009, 386: 407-416

23 Sasaki S, Yamagishi N, Yoshikawa N. Efficient virus-induced gene silencing in apple, pear and Japanese pear using apple latent spherical virus vectors. Plant Methods, 2011, 7: 15

24 Yamagishi N, Yoshikawa N. Virus-induced gene silencing in soybean seeds and the emergence stage of soybean plants with apple latent spherical virus vectors. Plant Mol Biol, 2009, 71: 15-24

25 Scofield S R, Nelson R S. Resources for virus-induced gene silencing in the grasses. Plant Physiol, 2009, 149: 152-157

26 van der Linde K, Kastner C, Kumlehn J, et al. Systemic virusinduced gene silencing allows functional characterization of maize genes during biotrophic interaction with Ustilago maydis. New Phytol, 2011, 189: 471-483

27 Bruun-Rasmussen M, Madsen C T, Jessing S, et al. Stability of barley stripe mosaic virus-induced gene silencing in barley. Mol Plant Microbe Interact, 2007, 20: 1323-1331

28 Pacak A, Geisler K, Jorgensen B, et al. Investigations of barley stripe mosaic virus as a gene silencing vector in barley roots and in Brachypodium distachyon and oat. Plant Methods, 2010, 6: 26

29 Scofield S R, Huang L, Brandt A S, et al. Development of a virus-induced gene-silencing system for hexaploid wheat and its use in functional analysis of the Lr21-mediated leaf rust resistance pathway. Plant Physiol, 2005, 138: 2165-2173

30 Yuan C, Li C, Yan L, et al. A high throughput barley stripe mosaic virus vector for virus induced gene silencing in monocots and dicots. PLoS ONE, 2011, 6: e26468

31 Zhang C, Bradshaw J D, Whitham S A, et al. The development of an efficient multipurpose bean pod mottle virus viral vector set for foreign gene expression and RNA silencing. Plant Physiol, 2010, 153: $52-65$

32 Zhang C, Ghabrial S A. Development of bean pod mottle virus-based vectors for stable protein expression and sequence-specific virus-induced gene silencing in soybean. Virology, 2006, 344: 401411

33 Zhang C, Yang C, Whitham S A, et al. Development and use of an efficient DNA-based viral gene silencing vector for soybean. Mol Plant Microbe Interact, 2009, 22: 123-131

34 Nagamatsu A, Masuta C, Senda M, et al. Functional analysis of soybean genes involved in flavonoid biosynthesis by virus-induced gene silencing. Plant Biotechnol J, 2007, 5: 778-790

$35 \mathrm{Lu} \mathrm{H} \mathrm{C,} \mathrm{Chen} \mathrm{H} \mathrm{H,} \mathrm{Tsai} \mathrm{W} \mathrm{C,} \mathrm{et} \mathrm{al.} \mathrm{Strategies} \mathrm{for} \mathrm{functional} \mathrm{valida-}$ tion of genes involved in reproductive stages of orchids. Plant Physiol, 2007, 143: 558-569

36 Burger C, Rondet S, Benveniste $\mathrm{P}$, et al. Virus-induced silencing of sterol biosynthetic genes: identification of a Nicotiana tabacum L. obtusifoliol-14alpha-demethylase (CYP51) by genetic manipulation of the sterol biosynthetic pathway in Nicotiana benthamiana L. J Exp Bot, 2003, 54: 1675-1683

37 Faivre-Rampant O, Gilroy E M, Hrubikova K, et al. Potato virus
$\mathrm{X}$-induced gene silencing in leaves and tubers of potato. Plant Physiol, 2004, 134: 1308-1316

38 Gammelgard E, Mohan M, Valkonen J P. Potyvirus-induced gene silencing: the dynamic process of systemic silencing and silencing suppression. J Gen Virol, 2007, 88: 2337-2346

39 Constantin G D, Gronlund M, Johansen I E, et al. Virus-induced gene silencing (VIGS) as a reverse genetic tool to study development of symbiotic root nodules. Mol Plant Microbe Interact, 2008, 21: $720-727$

40 Constantin G D, Krath B N, MacFarlane S A, et al. Virus-induced gene silencing as a tool for functional genomics in a legume species. Plant J, 2004, 40: 622-631

41 Gronlund M, Constantin G, Piednoir E, et al. Virus-induced gene silencing in Medicago truncatula and Lathyrus odorata. Virus Res, 2008, 135: 345-349

42 Naylor M, Reeves J, Cooper J I, et al. Construction and properties of a gene-silencing vector based on poplar mosaic virus (genus Carlavirus). J Virol Methods, 2005, 124: 27-36

43 Vaistij F E, Jones L. Compromised virus-induced gene silencing in RDR6-deficient plants. Plant Physiol, 2009, 149: 1399-1407

44 Varallyay E, Lichner Z, Safrany J, et al. Development of a virus induced gene silencing vector from a legumes infecting tobamovirus. Acta Biol Hung, 2010, 61: 457-469

45 Hiriart J B, Aro E M, Lehto K. Dynamics of the VIGS-mediated chimeric silencing of the Nicotiana benthamiana $\mathrm{ChlH}$ gene and of the tobacco mosaic virus vector. Mol Plant Microbe Interact, 2003, 16: $99-106$

46 Metzlaff M. RNA-mediated RNA degradation in transgene- and virus-induced gene silencing. Biol Chem, 2002, 383: 1483-1489

47 Gao Y, Zhang Y L, Zhang X F, et al. Development and optimization of Tobacco necrosis virus A induced gene silencing in Nicotiana benthamiana. Prog Biochem Biophys, 2011, 38: 919-928

48 Pignatta D, Kumar P, Turina M, et al. Quantitative analysis of efficient endogenous gene silencing in Nicotiana benthamiana plants using tomato bushy stunt virus vectors that retain the capsid protein gene. Mol Plant Microbe Interact, 2007, 20: 609-618

49 Brigneti G, Martin-Hernandez A M, Jin H, et al. Virus-induced gene silencing in Solanum species. Plant J, 2004, 39: 264-272

50 Burch-Smith T M, Schiff M, Liu Y, et al. Efficient virus-induced gene silencing in Arabidopsis. Plant Physiol, 2006, 142: 21-27

51 Chen J C, Jiang C Z, Gookin T E, et al. Chalcone synthase as a reporter in virus-induced gene silencing studies of flower senescence. Plant Mol Biol, 2004, 55: 521-530

52 Chung E, Seong E, Kim Y C, et al. A method of high frequency virus-induced gene silencing in chili pepper (Capsicum annuиm L. cv. Bukang). Mol Cells, 2004, 17: 377-380

53 Fu D Q, Zhu B Z, Zhu H L, et al. Virus-induced gene silencing in tomato fruit. Plant J, 2005, 43: 299-308

54 Fu D Q, Zhu B Z, Zhu H L, et al. Enhancement of virus-induced gene silencing in tomato by low temperature and low humidity. Mol Cells, 2006, 21: 153-160

55 Gao X, Wheeler T, Li Z, et al. Silencing GhNDR1 and GhMKK2 compromises cotton resistance to Verticillium wilt. Plant J, 2011, 66: 293-305

56 Gould B, Kramer E M. Virus-induced gene silencing as a tool for functional analyses in the emerging model plant aquilegia (columbine, Ranunculaceae). Plant Methods, 2007, 3: 6

57 Hileman L C, Drea S, Martino G, et al. Virus-induced gene silencing is an effective tool for assaying gene function in the basal eudicot species Papaver somniferum (opium poppy). Plant J, 2005, 44: 334341

58 Liu Y, Schiff M, Dinesh-Kumar S P. Virus-induced gene silencing in tomato. Plant J, 2002, 31: 777-786

59 Liu Y, Schiff M, Marathe R, et al. Tobacco Rar1, EDS1 and NPR1/ NIM1 like genes are required for N-mediated resistance to tobacco mosaic virus. Plant J, 2002, 30: 415-429

60 Ryu C M, Anand A, Kang L, et al. Agrodrench: a novel and effective agroinoculation method for virus-induced gene silencing in roots and diverse solanaceous species. Plant J, 2004, 40: 322-331 
61 Senthil-Kumar M, Hema R, Anand A, et al. A systematic study to determine the extent of gene silencing in Nicotiana benthamiana and other Solanaceae species when heterologous gene sequences are used for virus-induced gene silencing. New Phytol, 2007, 176: 782-791

62 Wege S, Scholz A, Gleissberg S, et al. Highly efficient virus-induced gene silencing (VIGS) in California poppy (Eschscholzia californica): an evaluation of VIGS as a strategy to obtain functional data from non-model plants. Ann Bot, 2007, 100: 641-649

63 Di Stilio V S, Kumar R A, Oddone A M, et al. Virus-induced gene silencing as a tool for comparative functional studies in Thalictrum. PLOS ONE, 2010, 5: e12064

64 Pflieger S, Blanchet S, Camborde L, et al. Efficient virus-induced gene silencing in Arabidopsis using a 'one-step' TYMV-derived vector. Plant J, 2008, 56: 678-690

65 Krenz B, Wege C, Jeske H. Cell-free construction of disarmed abutilon mosaic virus-based gene silencing vectors. J Virol Methods, 2010, 169: $129-137$

66 Golenberg E M, Sather D N, Hancock L C, et al. Development of a gene silencing DNA vector derived from a broad host range geminivirus. Plant Methods, 2009, 5: 9

67 Turnage M A, Muangsan N, Peele C G, et al. Geminivirus-based vectors for gene silencing in Arabidopsis. Plant J, 2002, 30: 107-114

68 Muruganantham M, Moskovitz Y, Haviv S, et al. Grapevine virus A-mediated gene silencing in Nicotiana benthamiana and Vitis vinifera. J Virol Methods, 2009, 155: 167-174

69 del Rosario Abraham-Juarez M, del Carmen Rocha-Granados M, Lopez M G, et al. Virus-induced silencing of Comt, pAmt and Kas genes results in a reduction of capsaicinoid accumulation in chili pepper fruits. Planta, 2008, 227: 681-695

70 Purkayastha A, Mathur S, Verma V, et al. Virus-induced gene silencing in rice using a vector derived from a DNA virus. Planta, 2010, 232: $1531-1540$

71 Carrillo-Tripp J, Shimada-Beltran H, Rivera-Bustamante R. Use of geminiviral vectors for functional genomics. Curr Opin Plant Biol, 2006, 9: 209-215

72 Pandey P, Choudhury N R, Mukherjee S K. A geminiviral amplicon (VA) derived from tomato leaf curl virus (ToLCV) can replicate in a wide variety of plant species and also acts as a VIGS vector. Virol J, 2009, 6: 152

73 Qian Y, Mugiira R B, Zhou X. A modified viral satellite DNA-based gene silencing vector is effective in association with heterologous begomoviruses. Virus Res, 2006, 118: 136-142

74 Lacomme C, Hrubikova K, Hein I. Enhancement of virus-induced gene silencing through viral-based production of inverted-repeats. Plant J, 2003, 34: 543-553

$75 \mathrm{Xu}$ P, Zhang Y, Kang L, et al. Computational estimation and experimental verification of off-target silencing during posttranscriptional gene silencing in plants. Plant Physiol, 2006, 142: 429-440

76 Jacob S S, Vanitharani R, Karthikeyan A S, et al. Mungbean yellow mosaic virus-Vi agroinfection by codelivery of DNA A and DNA B from one Agrobacterium strain. Plant Dis, 2003, 87: 247-251

77 Orzaez D, Mirabel S, Wieland W H, et al. Agroinjection of tomato fruits. A tool for rapid functional analysis of transgenes directly in fruit. Plant Physiol, 2006, 140: 3-11

78 Jaakola L, Poole M, Jones M O, et al. A SQUAMOSA MADS box gene involved in the regulation of anthocyanin accumulation in bilberry fruits. Plant Physiol, 2010, 153: 1619-1629

79 Chai Y M, Jia H F, Li C L, et al. FaPYR1 is involved in strawberry fruit ripening. J Exp Bot, 2011, 62: 5079-5089

80 Romero I, Tikunov Y, Bovy A. Virus-induced gene silencing in detached tomatoes and biochemical effects of phytoene desaturase gene silencing. J Plant Physiol, 2011, 168: 1129-1135

81 Liu Y, Schiff M, Dinesh-Kumar S P. Involvement of MEK1 MAPKK, NTF6 MAPK, WRKY/MYB transcription factors, COI1 and CTR1 in N-mediated resistance to tobacco mosaic virus. Plant J, 2004, 38: 800-809

82 Peart J R, Cook G, Feys B J, et al. An EDS1 orthologue is required for $\mathrm{N}$-mediated resistance against Tobacco mosaic virus. Plant $\mathrm{J}$,
2002, 29: 569-579

83 Peart J R, Mestre P, Lu R, et al. NRG1, a CC-NB-LRR protein, together with $\mathrm{N}$, a TIR-NB-LRR protein, mediates resistance against tobacco mosaic virus. Curr Biol, 2005, 15: 968-973

84 Zhu X, Caplan J, Mamillapalli P, et al. Function of endoplasmic reticulum calcium ATPase in innate immunity-mediated programmed cell death. EMBO J, 2010, 29: 1007-1018

85 Caplan J L, Mamillapalli P, Burch-Smith T M, et al. Chloroplastic protein NRIP1 mediates innate immune receptor recognition of a viral effector. Cell, 2008, 132: 449-462

86 Liu Y, Schiff M, Czymmek K, et al. Autophagy regulates programmed cell death during the plant innate immune response. Cell, 2005, 121: 567-577

87 Tameling W I, Baulcombe D C. Physical association of the NB-LRR resistance protein $\mathrm{Rx}$ with a Ran GTPase-activating protein is required for extreme resistance to potato virus X. Plant Cell, 2007, 19: 1682-1694

88 Jaag H M, Pogany J, Nagy P D. A host $\mathrm{Ca}^{2+} / \mathrm{Mn}^{2+}$ ion pump is a factor in the emergence of viral RNA recombinants. Cell Host Microbe, 2010, 7: 74-81

89 Barajas D, Nagy P D. Ubiquitination of tombusvirus p33 replication protein plays a role in virus replication and binding to the host Vps23p ESCRT protein. Virology, 2010, 397: 358-368

90 Wang R Y, Nagy P D. Tomato bushy stunt virus co-opts the RNA-binding function of a host metabolic enzyme for viral genomic RNA synthesis. Cell Host Microbe, 2008, 3: 178-187

91 Abbink T E, Peart J R, Mos T N, et al. Silencing of a gene encoding a protein component of the oxygen-evolving complex of photosystem II enhances virus replication in plants. Virology, 2002, 295: 307-319

92 Yoshii A, Shimizu T, Yoshida A, et al. NTH201, a novel class II KNOTTED1-like protein, facilitates the cell-to-cell movement of tobacco mosaic virus in tobacco. Mol Plant Microbe Interact, 2008, 21: $586-596$

93 Jin H, Li S, Villegas A Jr. Down-regulation of the 26S proteasome subunit RPN9 inhibits viral systemic transport and alters plant vascular development. Plant Physiol, 2006, 142: 651-661

94 Gronlund M, Olsen A, Johansen E I, et al. Protocol: using virus-induced gene silencing to study the arbuscular mycorrhizal symbiosis in Pisum sativum. Plant Methods, 2010, 6: 28

95 Gabriels S H, Takken F L, Vossen J H, et al. CDNA-AFLP combined with functional analysis reveals novel genes involved in the hypersensitive response. Mol Plant Microbe Interact, 2006, 19: 567-576

96 Gabriels S H, Vossen J H, Ekengren S K, et al. An NB-LRR protein required for HR signalling mediated by both extra- and intracellular resistance proteins. Plant J, 2007, 50: 14-28

97 Rowland O, Ludwig A A, Merrick C J, et al. Functional analysis of Avr9/Cf-9 rapidly elicited genes identifies a protein kinase, ACIK1, that is essential for full Cf-9-dependent disease resistance in tomato. Plant Cell, 2005, 17: 295-310

98 Vossen J H, Abd-El-Haliem A, Fradin E F, et al. Identification of tomato phosphatidylinositol-specific phospholipase-C (PI-PLC) family members and the role of PLC4 and PLC6 in HR and disease resistance. Plant J, 2010, 62: 224-239

99 Rivas S, Rougon-Cardoso A, Smoker M, et al. CITRX thioredoxin interacts with the tomato $\mathrm{Cf}-9$ resistance protein and negatively regulates defence. EMBO J, 2004, 23: 2156-2165

100 Stulemeijer I J, Stratmann J W, Joosten M H. Tomato mitogen-activated protein kinases LeMPK1, LeMPK2, and LeMPK3 are activated during the Cf-4/Avr4-induced hypersensitive response and have distinct phosphorylation specificities. Plant Physiol, 2007, 144: 1481- 1494

101 Eichmann R, Bischof M, Weis C, et al. BAX INHIBITOR-1 is required for full susceptibility of barley to powdery mildew. Mol Plant Microbe Interact, 2010, 23: 1217-1227

102 Hein I, Barciszewska-Pacak M, Hrubikova K, et al. Virus-induced gene silencing-based functional characterization of genes associated with powdery mildew resistance in barley. Plant Physiol, 2005, 138: 
2155-2164

103 Cloutier S, McCallum B D, Loutre C, et al. Leaf rust resistance gene $\mathrm{Lr} 1$, isolated from bread wheat (Triticum aestivum L.) is a member of the large psr567 gene family. Plant Mol Biol, 2007, 65: 93-106

104 Xie W, Hao L, Goodwin P H. Role of a xyloglucan-specific endo-beta-1,4-glucanase inhibitor in the interactions of Nicotiana benthamiana with Colletotrichum destructivum, C. orbiculare or Pseudomonas syringae pv. tabaci. Mol Plant Pathol, 2008, 9: 191-202

105 Borras-Hidalgo O, Thomma B P, Collazo C, et al. EIL2 transcription factor and glutathione synthetase are required for defense of tobacco against tobacco blue mold. Mol Plant Microbe Interact, 2006, 19: 399-406

106 Ekengren S K, Liu Y L, Schiff M, et al. Two MAPK cascades, NPR1, and TGA transcription factors play a role in Pto-mediated disease resistance in tomato. Plant Journal, 2003, 36: 905-917

107 Chandok M R, Ekengren S K, Martin G B, et al. Suppression of pathogen-inducible NO synthase (iNOS) activity in tomato increases susceptibility to Pseudomonas syringae. Proc Natl Acad Sci USA, 2004, 101: 8239-8244

108 Kanzaki H, Saitoh H, Ito A, et al. Cytosolic HSP90 and HSP70 are essential components of INF1-mediated hypersensitive response and non-host resistance to Pseudomonas cichorii in Nicotiana benthamiana. Mol Plant Pathol, 2003, 4: 383-391

109 Maimbo M, Ohnishi K, Hikichi Y, et al. S-glycoprotein-like protein regulates defense responses in Nicotiana plants against Ralstonia solanacearum. Plant Physiol, 2010, 152: 2023-2035

110 Sharma P C, Ito A, Shimizu T, et al. Virus-induced silencing of WIPK and SIPK genes reduces resistance to a bacterial pathogen, but has no effect on the INF1-induced hypersensitive response (HR) in Nicotiana benthamiana. Mol Genet Genomics, 2003, 269: 583591

111 Hwang I S, Hwang B K. Role of the pepper cytochrome P450 gene CaCYP450A in defense responses against microbial pathogens. Planta, 2010, 232: 1409-1421

112 Leister R T, Dahlbeck D, Day B, et al. Molecular genetic evidence for the role of SGT1 in the intramolecular complementation of Bs2 protein activity in Nicotiana benthamiana. Plant Cell, 2005, 17: $1268-1278$

113 Lee D H, Choi H W, Hwang B K. The pepper E3 ubiquitin ligase RING1 gene, CaRING1, is required for cell death and the salicylic aciddependent defense response. Plant Physiol, 2011, 156: 2011-2025

114 Melech-Bonfil S, Sessa G. The SIMKK2 and SIMPK2 genes play a role in tomato disease resistance to Xanthomonas campestris pv. vesicatoria. Plant Signal Behav, 2011, 6: 154-156

115 Schornack S, Ballvora A, Gurlebeck D, et al. The tomato resistance protein Bs4 is a predicted non-nuclear TIR-NB-LRR protein that mediates defense responses to severely truncated derivatives of AvrBs4 and overexpressed AvrBs3. Plant J, 2004, 37: 46-60

116 Bhattarai K K, Atamian H S, Kaloshian I, et al. WRKY72-type transcription factors contribute to basal immunity in tomato and $\mathrm{Ar}$ abidopsis as well as gene-for-gene resistance mediated by the tomato R gene Mi-1. Plant J, 2010, 63: 229-240

117 Bhattarai K K, Li Q, Liu Y, et al. The MI-1-mediated pest resistance requires Hsp90 and Sgt1. Plant Physiol, 2007, 144: 312-323

118 Jablonska B, Ammiraju J S, Bhattarai K K, et al. The Mi-9 gene from Solanum arcanum conferring heat-stable resistance to root-knot nematodes is a homolog of Mi-1. Plant Physiol, 2007, 143: 1044-1054

119 Li Q, Xie Q G, Smith-Becker J, et al. Mi-1-Mediated aphid resistance involves salicylic acid and mitogen-activated protein kinase signaling cascades. Mol Plant Microbe Interact, 2006, 19: 655-664

120 Mantelin S, Peng $\mathrm{H} \mathrm{C}$, Li B, et al. The receptor-like kinase SISERK1 is required for Mi-1-mediated resistance to potato aphids in tomato. Plant J, 2011, 67: 459-471

121 Kang J H, Wang L, Giri A, et al. Silencing threonine deaminase and JAR4 in Nicotiana attenuata impairs jasmonic acid-isoleucine-mediated defenses against Manduca sexta. Plant Cell, 2006, 18: 3303 3320

122 Lou Y, Baldwin I T. Silencing of a germin-like gene in Nicotiana attenuata improves performance of native herbivores. Plant Physiol, 2006, 140: 1126-1136

123 Kandoth P K, Ranf S, Pancholi S S, et al. Tomato MAPKs LeMPK1, LeMPK2, and LeMPK3 function in the systemin-mediated defense response against herbivorous insects. Proc Natl Acad Sci USA, 2007, 104: 12205-12210

124 Heinrich M, Baldwin I T, Wu J. Two mitogen-activated protein kinase kinases, MKK1 and MEK2, are involved in wounding- and specialist lepidopteran herbivore Manduca sexta-induced responses in Nicotiana attenuata. J Exp Bot, 2011, 62: 4355-4365

125 Yang D H, Hettenhausen C, Baldwin I T, et al. BAK1 regulates the accumulation of jasmonic acid and the levels of trypsin proteinase inhibitors in Nicotiana attenuata's responses to herbivory. J Exp Bot, 2010, 62: 641-652

126 Senthil-Kumar M, Udayakumar M. High-throughput virus-induced gene-silencing approach to assess the functional relevance of a moisture stress-induced cDNA homologous to lea4. J Exp Bot, 2006, 57: 2291-2302

127 Guo Y, Huang C, Xie Y, et al. A tomato glutaredoxin gene SIGRX1 regulates plant responses to oxidative, drought and salt stresses. Planta, 2010, 232: 1499-1509

128 Lee S C, Choi du S, Hwang I S, et al. The pepper oxidoreductase $\mathrm{CaOXR} 1$ interacts with the transcription factor CaRAV1 and is required for salt and osmotic stress tolerance. Plant Mol Biol, 2010, 73: 409-424

129 Ahn C S, Lee J H, Reum Hwang A, et al. Prohibitin is involved in mitochondrial biogenesis in plants. Plant J, 2006, 46: 658-667

130 Re D A, Dezar C A, Chan R L, et al. Nicotiana attenuata NaHD20 plays a role in leaf ABA accumulation during water stress, benzylacetone emission from flowers, and the timing of bolting and flower transitions. J Exp Bot, 2011, 62: 155-166

131 Senthil-Kumar M, Govind G, Kang L, et al. Functional characterization of Nicotiana benthamiana homologs of peanut water deficitinduced genes by virus-induced gene silencing. Planta, 2007, 225: 523-539

132 Hands P, Vosnakis N, Betts D, et al. Alternate transcripts of a floral developmental regulator have both distinct and redundant functions in opium poppy. Ann Bot, 2011, 107: 1557-1566

133 Kramer E M, Holappa L, Gould B, et al. Elaboration of B gene function to include the identity of novel floral organs in the lower eudicot Aquilegia. Plant Cell, 2007, 19: 750-766

134 Liu Y, Nakayama N, Schiff M, et al. Virus induced gene silencing of a DEFICIENS ortholog in Nicotiana benthamiana. Plant Mol Biol, 2004, 54: 701-711

135 Dong Y, Burch-Smith T M, Liu Y, et al. A ligation-independent cloning tobacco rattle virus vector for high-throughput virus-induced gene silencing identifies roles for NbMADS4-1 and -2 in floral development. Plant Physiol, 2007, 145: 1161-1170

136 Chen J C, Jiang C Z, Reid M S. Silencing a prohibitin alters plant development and senescence. Plant J, 2005, 44: 16-24

137 Kang Y W, Kim R N, Cho H S, et al. Silencing of a BYPASS1 homolog results in root-independent pleiotrophic developmental defects in Nicotiana benthamiana. Plant Mol Biol, 2008, 68: 423-437

138 Bouvier F, Linka N, Isner J C, et al. Arabidopsis SAMT1 defines a plastid transporter regulating plastid biogenesis and plant development. Plant Cell, 2006, 18: 3088-3105

139 Park J A, Ahn J W, Kim Y K, et al. Retinoblastoma protein regulates cell proliferation, differentiation, and endoreduplication in plants. Plant J, 2005, 42: 153-163

140 Valentine T, Shaw J, Blok V C, et al. Efficient virus-induced gene silencing in roots using a modified tobacco rattle virus vector. Plant Physiol, 2004, 136: 3999-4009

141 Liu B, Watanabe S, Uchiyama T, et al. The soybean stem growth habit gene Dt1 is an ortholog of Arabidopsis TERMINAL FLOWER1. Plant Physiol, 2010, 153: 198-210

142 Burton R A, Gibeaut D M, Bacic A, et al. Virus-induced silencing of a plant cellulose synthase gene. Plant Cell, 2000, 12: 691-706

143 Held M A, Penning B, Brandt A S, et al. Small-interfering RNAs from natural antisense transcripts derived from a cellulose synthase 
gene modulate cell wall biosynthesis in barley. Proc Natl Acad Sci USA, 2008, 105: 20534-20539

144 Stewart C Jr, Kang B C, Liu K, et al. The Pun1 gene for pungency in pepper encodes a putative acyltransferase. Plant J, 2005, 42: 675-688

145 Ahn J W, Verma R, Kim M, et al. Depletion of UDP-D-apiose/ UDP-D-xylose synthases results in rhamnogalacturonan-II deficiency, cell wall thickening, and cell death in higher plants. J Biol Chem, 2006, 281: 13708-13716

146 Asai S, Mase K, Yoshioka H. A key enzyme for flavin synthesis is required for nitric oxide and reactive oxygen species production in disease resistance. Plant J, 2010, 62: 911-924

147 Anand A, Vaghchhipawala Z, Ryu C M, et al. Identification and characterization of plant genes involved in Agrobacterium-mediated plant transformation by virus-induced gene silencing. Mol Plant Microbe Interact, 2007, 20: 41-52

148 Jones L, Keining T, Eamens A, et al. Virus-induced gene silencing of argonaute genes in Nicotiana benthamiana demonstrates that extensive systemic silencing requires Argonaute1-like and Argonaute4-like genes. Plant Physiol, 2006, 141: 598-606

149 Kim M, Lim J H, Ahn C S, et al. Mitochondria-associated hexokinases play a role in the control of programmed cell death in Nicotiana benthamiana. Plant Cell, 2006, 18: 2341-2355

150 Kim Y K, Lee J Y, Cho H S, et al. Inactivation of organellar glutamyland seryl-tRNA synthetases leads to developmental arrest of chloroplasts and mitochondria in higher plants. J Biol Chem, 2005, 280: 37098-37106

151 Lin Z, Yin K, Wang X, et al. Virus induced gene silencing of AtCDC5 results in accelerated cell death in Arabidopsis leaves. Plant Physiol Biochem, 2007, 45: 87-94

152 Park Y J, Cho H K, Jung H J, et al. PRBP plays a role in plastid ribosomal RNA maturation and chloroplast biogenesis in Nicotiana benthamiana. Planta, 2011, 233: 1073-1085

153 Ahn C S, Lee J H, Pai H S. Silencing of NbNAP1 encoding a plastidic SufB-like protein affects chloroplast development in Nicotiana benthamiana. Mol Cells, 2005, 20: 112-118

154 Cho H S, Lee S S, Kim K D, et al. DNA gyrase is involved in chloroplast nucleoid partitioning. Plant Cell, 2004, 16: 2665-2682

155 Arsova B, Hoja U, Wimmelbacher M, et al. Plastidial thioredoxin z interacts with two fructokinase-like proteins in a thiol-dependent manner: evidence for an essential role in chloroplast development in Arabidopsis and Nicotiana benthamiana. Plant Cell, 2010, 22: 1498-1515

156 Jeon Y, Hwang A R, Hwang I, et al. Silencing of NbCEP1 encoding a chloroplast envelope protein containing 15 leucine-rich-repeats disrupts chloroplast biogenesis in Nicotiana benthamiana. Mol Cells, 2010, 29: 175-183

157 Kang Y W, Lee J Y, Jeon Y, et al. In vivo effects of NbSiR silencing on chloroplast development in Nicotiana benthamiana. Plant Mol Biol, 2010, 72: 569-583

158 Fan J, Quan S, Orth T, et al. The Arabidopsis PEX12 gene is required for peroxisome biogenesis and is essential for development. Plant Physiol, 2005, 139: 231-239

159 Li R, Reed D W, Liu E, et al. Functional genomic analysis of alkaloid biosynthesis in Hyoscyamus niger reveals a cytochrome $\mathrm{P} 450$ involved in littorine rearrangement. Chem Biol, 2006, 13: 513-520

160 Liscombe D K, O'Connor S E. A virus-induced gene silencing approach to understanding alkaloid metabolism in Catharanthus roseus. Phytochemistry, 2011, 72: 1969-1977

161 Todd A T, Liu E, Polvi S L, et al. A functional genomics screen identifies diverse transcription factors that regulate alkaloid biosynthesis in Nicotiana benthamiana. Plant J, 2010, 62: 589-600

162 Page J E, Hause G, Raschke M, et al. Functional analysis of the final steps of the 1-deoxy-D-xylulose 5-phosphate (DXP) pathway to isoprenoids in plants using virus-induced gene silencing. Plant Physiol, 2004, 134: 1401-1413

163 Ahn C S, Pai H S. Physiological function of IspE, a plastid MEP pathway gene for isoprenoid biosynthesis, in organelle biogenesis and cell morphogenesis in Nicotiana benthamiana. Plant Mol Biol, 2008, 66: 503-517

164 Qian W, Yu C, Qin H, et al. Molecular and functional analysis of phosphomannomutase (PMM) from higher plants and genetic evidence for the involvement of PMM in ascorbic acid biosynthesis in Arabidopsis and Nicotiana benthamiana. Plant J, 2007, 49: 399-413

165 Darnet S, Rahier A. Plant sterol biosynthesis: identification of two distinct families of sterol 4alpha-methyl oxidases. Biochem J, 2004, 378: 889-898

166 Park J A, Kim T W, Kim S K, et al. Silencing of NbECR encoding a putative enoyl-CoA reductase results in disorganized membrane structures and epidermal cell ablation in Nicotiana benthamiana. FEBS Lett, 2005, 579: 4459-4464

167 Tang Y, Wang F, Zhao J, et al. Virus-based microRNA expression for gene functional analysis in plants. Plant Physiol, 2010, 153: 632-641

168 Lacorte C, Ribeiro S G, Lohuis D, et al. Potato virus X and Tobacco mosaic virus-based vectors compatible with the Gateway cloning system. J Virol Methods, 2010, 164: 7-13

Open Access This article is distributed under the terms of the Creative Commons Attribution License which permits any use, distribution, and reproduction in any medium, provided the original author(s) and source are credited. 